\title{
Lysosomal acid lipase activity in children with dyslipidemia and hepatic dysfunction
}

\author{
Beyhan Özkaya ${ }^{1}$, Ebru Canda $^{1}$, Melis Köse ${ }^{1}$, Mehtap Kağnıci $^{1}$, EserY Sözmen², Mahmut Çoker ${ }^{2}$ and Sema K Uçar $^{1,2 *}$ \\ ${ }^{1}$ Department of Pediatrics, Division of Metabolism and Nutrition, Ege University Medical Faculty, Bornova, Izmir, Turkey \\ ${ }^{2}$ Department of Medical Biochemistry, Ege University Medical Faculty, Bornova, Izmir, Turkey
}

\begin{abstract}
Background: Lysosomal acid lipase (LAL) enzyme, is responsible for the hydrolysis of intracellular triacylglycerol and cholesterol esters. We investigate the LAL activity (LAL-A) in patients with hepatic dysfunction and/or dyslipidemia and determine the associated clinical and biochemical parameters.

Methods: This prospective, cross-sectional study included 360 children ( 3 months -18 years; 40 control, and 320 screening patients). Demographic data, major clinical and laboratory findings, LAL-A and possible biomarkers were evaluated. Screening group was divided into two: LAL-A<0.6 nmol/ml/h (Group1); LAL-A $\geq 0.6 \mathrm{nmol} / \mathrm{ml} / \mathrm{h}$ (Group 2). LAL-A predictive model was evaluated using logistic regression.

Results: The mean LAL-A in the screening group $(1.43 \pm 2.05(0.03-16.8) \mathrm{nmol} / \mathrm{ml} / \mathrm{h}$ ) was significantly reduced compare to controls ( $<<0.001)$. No LAL deficiency was detected. There was a negative correlation between LAL-A and low-density lipoprotein cholesterol, triglyceride, and alanine aminotransferase (ALT) levels. LAL-A in patients with chronic fatigue $(p=0.002)$, hepatomegaly $(p=0.013)$ and splenomegaly $(p=0.001)$ were significantly lower compare to those without. The median thiobarbituric acid reactive substances, myeloperoxidase, chitotriosidase, hs-CRP, Citokeratin levels in Group 1 were higher compare to the controls ( $\mathrm{p}<0.005$ ).

Conclusions: LAL-A was reduced in paediatric patients with dyslipidemia and/or elevated transaminase. Our final multivariable predictive model for reduced LAL-A included: ALT, triglyceride, and hepatomegaly.
\end{abstract}

\begin{abstract}
Abbreviations: ALT: Alanine Aminotransferase; AST: Aspartate Aminotransferase; BMI: Body Mass Index; CESD: Cholesteryl Ester Storage Disease; CI: Confidence Interval; HDL-C: Low-Density Lipoprotein Cholesterol; hsCRP: High-Sensitivity C-Reactive Protein; LAL: Lysosomal Acid Lipase; LAL-A: LAL activity; LDL-C: High-Density Lipoprotein Cholesterol; MPO: Myeloperoxidase; OR: Odds Ratio; R: Reduced; SR: Significantly Reduced; TBARS: Thiobarbituric Acid Reactive Substances.
\end{abstract}

\section{Introduction}

Pediatric lysosomal acid lipase (LAL) deficiency caused by LIPA gene mutations is associated with two phenotypes Wolman's disease and Cholesteryl ester storage disease (CESD). Deficiency in LAL activity (LAL-A) $(<1 \%$ in Wolman's disease, $1-12 \%$ of the normal in CESD) leads to impaired hydrolysis of intracellular triacylglycerol and cholesterol esters [1-3].

Clinically, LAL deficiency is manifested by hepatosplenomegaly, hepatosteatosis, hepatic insufficiency, elevations in transaminases, total cholesterol, low-density lipoprotein cholesterol (LDL) and triglyceride levels, decreased in high-density lipoprotein cholesterol (HDL-C) and atherosclerosis [4]. So, lipid metabolism - dyslipidemia [1,5,6] and hepatic involvement [7] are hot topics in the in investigation of children with LAL deficiency.

In this study, the aim was to perform a selective LAL-A screening in pediatric patients with hepatic dysfunction and/or dyslipidemia, and investigate the clinical and laboratory biomarkers chitotriosidase (used in the diagnosis and follow-up of lysosomal diseases), cytokeratin-18 (plays a role in apoptosis in non-alcoholic steatohepatitis), hsCRP (a valuable indicator in atherosclerosis and non-alcoholic steatohepatitis), thiobarbituric acid reactive substances (TBARS) and myeloperoxidase (MPO) (important roles in lipid peroxidation) which might be connected with LAL activity.

\section{Material and methods}

\section{Subject sampling}

Patients (3 months - 18 years old) with unexplained liver dysfunction (presented with at least one of the following finding: persistent elevation in ALT and/or AST, hepatomegaly, hepatic steatosis) and/ or dyslipidemia (presented with at least one of the following finding: high LDL-C ( $\geq 160 \mathrm{mg} / \mathrm{dl})$, low HDL-C ( $\leq 35 \mathrm{mg} / \mathrm{dl})$ ) were included. Patients with obesity, liver disease of known etiology and genetically confirmed familial hyperlipidemia (LDLR, APOB and PCSK9) were excluded from the study. Consent forms were obtained from the children and their parents. The study was approved by Local Ethics Committee.

\section{Data collection}

Height and weight measurements were made at the admission. Body mass index (BMI) for each patient was calculated as weight

*Correspondence to: Sema Kalkan Uçar, Department of Pediatrics, Division of Metabolism and Nutrition, Ege University Medical Faculty, Bornova, Izmir, Turkey, Tel: 90.232.390.1037, E-mail: semakalkan@hotmail.com

Key words: lysosomal acid lipase activity, pediatric patients

Received: May 19, 2020; Accepted: June 15, 2020; Published: June 18, 2020 
(kg) divided by height (meters) squared. Lipid profile, hematological, biochemical parameters and abdominal USG findings were evaluated. LAL-A and sphingomyelinase (reference enzyme) were measured from all patients, whereas chitotriosidase, hsCRP, cytokeratin-18, MPO and TBARS were evaluated only from patients with reduced LAL-A.

\section{Methods}

LAL-A was measured fluorometrically using 4-methylumbelliferyl palmitate substrates in dry blood sample [8]. Samples were measured within two weeks and LAL activity was reported after two measurements. Screening group was divided into two groups: $\mathrm{LAL}-\mathrm{A}<0.6 \mathrm{nmol} / \mathrm{ml} / \mathrm{h}$ (Group 1); LAL-A $\geq 0.6 \mathrm{nmol} / \mathrm{ml} / \mathrm{h}$ (Group 2). Chitotriosidase enzyme activity was measured after the incubation of patient serum at $37^{\circ} \mathrm{C}$ for about 3 hours, fluorescence formed by the addition of ethylenediamine solution and was read as fluorometric excitation: $360 \mathrm{~nm}$, emission: $445 \mathrm{~nm}$ [9]. Patients with very low chitotriosidase activity that might be genetic deficient were excluded from the study. Serum hsCRP levels were measured using the CRP HS ELISA kit (DRG DiagnosticsEIA-3954) based on monoclonal antibody. All serum samples were analyzed in duplicate at the same time with the ELISA kit (Cloud-Clone Corp. SEB231Hu, for cytokeratin 18-human) in which KRT-18 specific antibody coated plates was used for measurement of Cytokeratin-18. For measurement of myeloperoxidase activity, the serum sample was diluted to $1 / 20$ with phosphate buffer. After centrifugation, the supernatant was separated. Hexadecyl trimethyl ammonium bromide was added onto 50 microliters of serum homogenate and then the sample was frozen 3 times at $-80^{\circ} \mathrm{C}$. Then o-dianisidine was added on to 30 microliters of each sample and absorbance values were recorded for 10 minutes at $460 \mathrm{~nm}$. TBARS was measured after addition of $1 \mathrm{~mL}$ of thiobarbituric acid solution to $0.5 \mathrm{~mL}$ of serum. After 20 minutes boiling of $100^{\circ} \mathrm{C}$ and centrifuging at $2000 \mathrm{rpm}$ for 10 minutes, colorimetric measurement was made at $532 \mathrm{~nm}$ wavelength in the supernatant.

\section{Statistical analysis}

All analyzes were performed using SPSS 17.0 statistical package program. The relationship between categorical variables was tested by Chi-square test and the relationship between numerical variables was analyzed by Spearman Correlation analysis. Mann Whitney U Test was used for comparison of two independent median values. Univariable associations with a reduced LAL activity were evaluated using logistic regression models and summarized with odds ratios (OR) and 95\% confidence intervals (CIs). A multivariable model was developed using stepwise selection, with the $P$ value for a feature to enter or leave the model set to 0.05 .

\section{Results}

360 children aged 3 months -18 years were included in the study. In the selection of the cases, the presence of at least one of dyslipidemia, hepatosteatosis, hepatomegaly or transaminase elevation was requested (N: 320). Healthy children were nominated as control group ( $\mathrm{N}: 40$ ) and they were matched for age and gender with the screening group.

The median age of all subjects was 5.5 (3 months -18) years. Consanguineous marriage in the screening group was significantly high $115(31 \%)(\mathrm{p}<0.05)$. Familial hyperlipidemia was observed in $130(36 \%)$ patients. Characteristics of screening patients and control group were presented at table 1 . Weight, height, hemoglobin, platelet, parameters, HDL-C, urea, creatinine, albumin were significantly low, whereas LDL-C, Triglyceride, AST, ALT, total bilirubin were significantly high in the screening group $(\mathrm{p}<0.05)$.
Table 1. Demographic and laboratory characteristics of the investigated patients

\begin{tabular}{|c|c|c|}
\hline & Control $(n=40)$ & Screening $(n=320)$ \\
\hline Age (months-year) & 7 (3 months-17years) & 4 (3 months-18years) \\
\hline \multicolumn{3}{|l|}{ Gender $(n, \%)$} \\
\hline Girl & $23(\% 57.5)$ & $183(\% 57.2)$ \\
\hline Boy & $17(\% 42.5)$ & $137(\% 42.8)$ \\
\hline Weight SDS* & $0.225((-1.92)-1.58)$ & $-0.76((-5.7)-2.48)$ \\
\hline Height SDS* & $0.135((-1.88)-1.81)$ & $-0.81((-5.4)-2.2)$ \\
\hline $\mathrm{Hb}(g / d l)^{*}$ & $12.7(10.3-15.3)$ & $11.7(6.7-16.3)$ \\
\hline $\operatorname{MCV}(f / L)$ & $81(66-89)$ & $79.1(67-106)$ \\
\hline Leukocytes $\left(10^{\wedge} 3 / \mu \mathrm{L}\right)$ & $8520(4370-15900)$ & $8590(1760-32400)$ \\
\hline Platelet $\left(10^{\wedge} 3 / \mu \mathrm{L}\right)^{*}$ & $326500(156000-597000)$ & $302000(35000-1097000)$ \\
\hline INR & $0.92(0.72-1.1)$ & $0.98(0.6-2.4)$ \\
\hline Total Cholesterol (mg / dl) & $150.5(115-175)$ & $146(54-340)$ \\
\hline LDL Cholesterol (mg / dl) * & $85(55-109)$ & $93(12-249)$ \\
\hline HDL Cholesterol (mg / dl) * & $48(36-70)$ & $26(3-44)$ \\
\hline Triglyceride $(\mathrm{mg} / \mathrm{dl}) *$ & $81(27-120)$ & $135(13-2180)$ \\
\hline $\operatorname{ALT}(\mathrm{U} / \mathrm{L}) *$ & $16(8-30)$ & $51(3-1761)$ \\
\hline $\operatorname{AST}(\mathrm{U} / \mathrm{L}) *$ & $28(15-37)$ & $44(12-1860)$ \\
\hline Glucose (mg / dl) & $84(61-118)$ & $87(26-146)$ \\
\hline Total Bilirubin $(\mathrm{mg} / \mathrm{dl}) *$ & $0.42(0.08-1.2)$ & $0.54(0.09-23)$ \\
\hline Direct Bilirubin (mg / dl) & $0.09(0-0.66)$ & $0.10(0.01-15)$ \\
\hline Urea $(\mathrm{mg} / \mathrm{dl}) *$ & $23.5(12-42)$ & $21(4-76)$ \\
\hline Creatinine $(\mathrm{mg} / \mathrm{dl}){ }^{*}$ & $0.5(0.27-1)$ & $0.3(0.1-4.8)$ \\
\hline Albumin $(\mathrm{g} / \mathrm{dl}) *$ & $4.3(3.2-5)$ & $3.7(1.6-5.2)$ \\
\hline
\end{tabular}

*: Statistically significant difference between the two groups $(\mathrm{p}<0.05)$; ALT: Alanine Aminotransferase; AST: Aspartate Aminotransferase; HDL: High-Density Lipoprotein Cholesterol ; INR: International Normalized Ratio; LDL: Low-Density Lipoprotein Cholesterol; Hb: Hemoglobin; MCV: Mean Corpuscular Volume

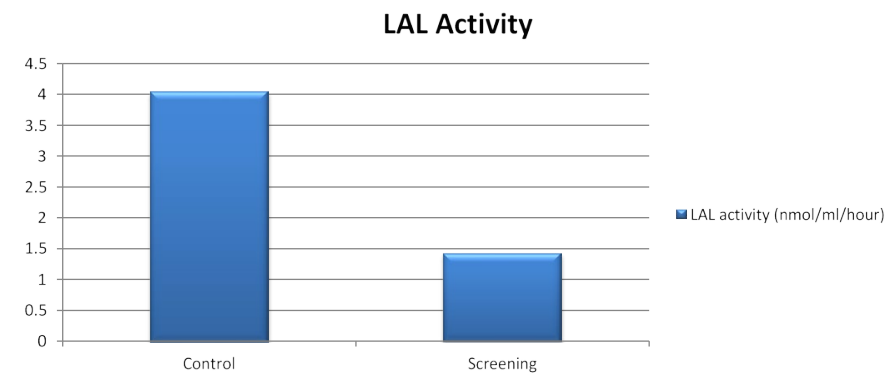

Figure 1. LAL activity of control and screening groups

The mean LAL-A in the screening group was $1.43 \pm 2.05(0.03-16.8)$ $\mathrm{nmol} / \mathrm{ml} / \mathrm{h}$; significantly lower comparing to the healthy controls $(\mathrm{p}<$ $0.001)$. No LAL deficiency ( $\mathrm{LAL}<0.03 \mathrm{nmol} / \mathrm{ml} / \mathrm{h}$ ) was detected (Figure 1 ).

To investigate the relationship between LAL-A and other clinical and laboratory biomarkers, patients were divided into two groups: Group 1 (LAL-A $<0.6 \mathrm{nmol} / \mathrm{ml} / \mathrm{h}$ (significantly reduced) and Group 2 (LAL-A $\geq 0.6 \mathrm{nmol} / \mathrm{ml} / \mathrm{h}$ (reduced). The reference interval was defined as $0.26-6.2 \mathrm{nmol} / \mathrm{ml} /$ hour. LAL-A below the tenth percentile $(0.6 \mathrm{nmol} /$ $\mathrm{ml} / \mathrm{h}$ ) was accepted as a cut-off for the enzyme sufficiency.

The clinical and laboratory characteristics of patients from Group 1 compared to the Group 2 were shown in the presence of splenomegaly lower the mean LAL-A to $0.36 \mathrm{nmol} / \mathrm{ml} / \mathrm{h}(0.03-0.49)(\mathrm{p}=0.001)$. Total cholesterol levels were higher $(\mathrm{p}=0.033)$, and HDL-C was lower in Group $1(\mathrm{p}=0.017)$ (Table 2).

Assessment of the possible clinical factors affecting LAL-A was performed by analyzing each parameter: age, gender, growth retardation, chronic fatigue symptoms, hepatomegaly, jaundice, splenomegaly, 


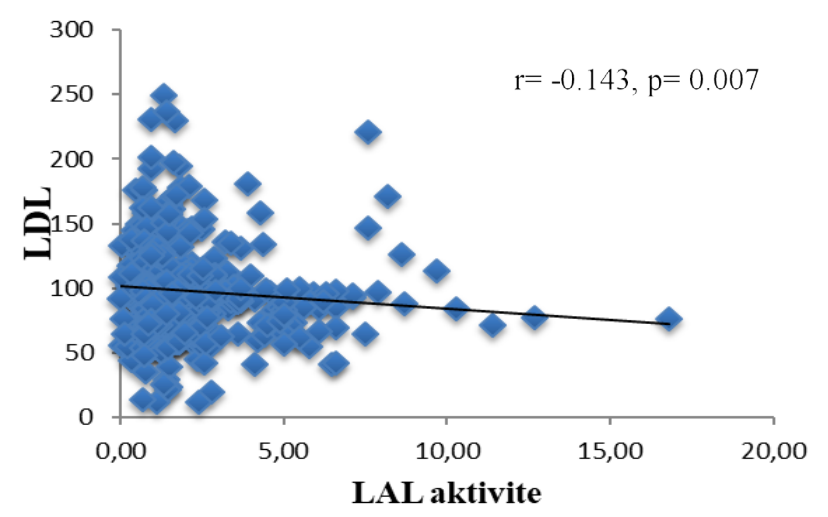

(A)

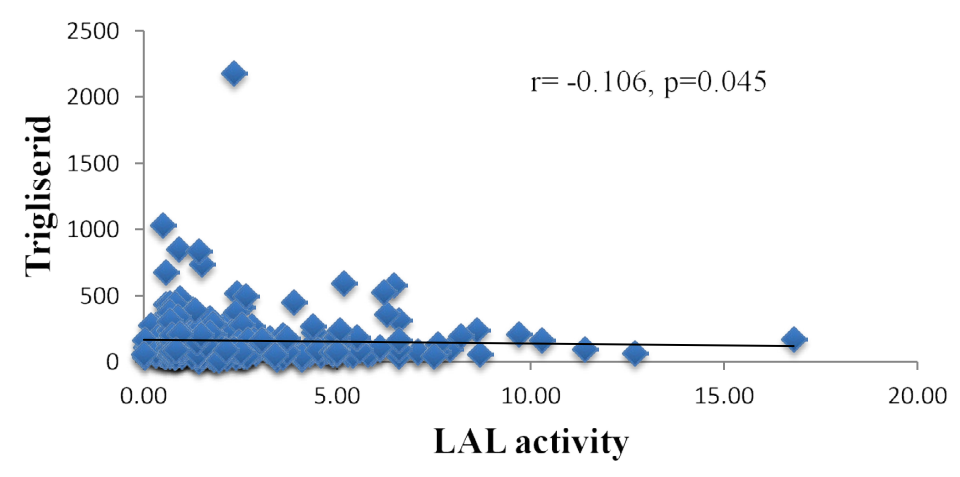

(B)

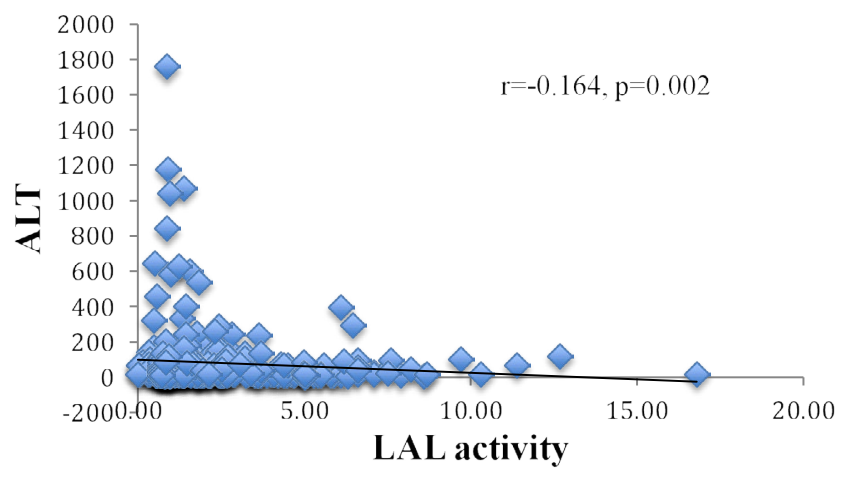

(C)

Figure 2. Relationship between LAL activity and LDL-cholesterol levels (A), triglyceride levels (B), ALT levels (C).

Table 2. Symptoms and clinical findings based on LAL level in the screening group

\begin{tabular}{|l|l|l|}
\hline & $\begin{array}{l}\text { Group 1 (N=45) } \\
\text { (significantly reduced LAL-A/ } \\
(\boldsymbol{n}, \% / \text { min-max) }\end{array}$ & $\begin{array}{l}\text { Group 2 (N=275) } \\
\text { (reduced LAL-A/ } \\
(\boldsymbol{n}, \% / \text { min-max) }\end{array}$ \\
\hline Abdominal distension & $10(\% 22.2)$ & $36(\% 13.1)$ \\
\hline Abdominal pain & $8(\% 17.8)$ & $36(\% 13.1)$ \\
\hline Chronic fatigue & $11(\% 24.4)$ & $67(\% 24.4)$ \\
\hline Diarrhea & $1(\% 2.2)$ & $9(\% 3.3)$ \\
\hline Growth retardation & $7(\% 15.6)$ & $76(\% 27.6)$ \\
\hline Hepatomegaly & $15(\% 33.3)$ & $71(\% 25.8)$ \\
\hline Splenomegaly $*$ & $13(\% 28.9)$ & $45(\% 16.4)$ \\
\hline Hypertension & $10(\% 22.2)$ & $34(\% 12.4)$ \\
\hline Jaundice & $6(\% 13.3)$ & $22(\% 8)$ \\
\hline Total Cholesterol $(\mathrm{mg} / \mathrm{dl}) *$ & $156(101-250)$ & $144(54-340)$ \\
\hline LDL -Cholesterol $(\mathrm{mg} / \mathrm{dl})$ & $108(44-176)$ & $91(12-249)$ \\
\hline HDL- Cholesterol $(\mathrm{mg} / \mathrm{dl}) *$ & $27(7-44)$ & $26(3-44)$ \\
\hline Triglyceride $(\mathrm{mg} / \mathrm{dl})$ & $151(38-1034)$ & $134(13-2180)$ \\
\hline ALT (U / L) & $65(10-648)$ & $48(3-1761)$ \\
\hline AST (U / L) & $43(16-1860)$ & $44(12-989)$ \\
\hline GGT (U / L) & $15(5-389)$ & $17(3-586)$ \\
\hline ALP (U / L) & $160(20-869)$ & $169(34-2790)$ \\
\hline & & \\
\hline
\end{tabular}

*: Statistically significant difference between the two groups $(\mathrm{p}<0.05)$. GGT: g-glutamyl transpeptidase; ALP: Alkaline Phosphatase; ALT: Alanine Aminotransferase; AST: Aspartate Aminotransferase

USG findings. Patients with chronic fatigue have the lowest LAL-A $(0.46(0.03-0.59) \mathrm{nmol} / \mathrm{ml} / \mathrm{h})$, significantly different $(\mathrm{p}=0.002)$ from those without fatigue $(1.80(0.66-16.8)) \mathrm{nmol} / \mathrm{ml} / \mathrm{h}$. LAL-A in patients with accompanying hepatomegaly was $0.48(0.03-0.59) \mathrm{nmol} / \mathrm{ml} / \mathrm{h})$, significantly lower $(\mathrm{p}=0.013)$ to those without hepatomegaly $(1.79$ $(0.66-12.79 \mathrm{nmol} / \mathrm{ml} / \mathrm{h})$. Although the mean LAL-A (1.02 (0.03-10.3) $\mathrm{nmol} / \mathrm{ml} / \mathrm{h})$ of $22(7 \%)$ in patients with hepatosteatosis on USG was lower than those with no hepatosteatosis $(1.44(0.04-16.8) \mathrm{nmol} / \mathrm{ml} / \mathrm{h})$, the difference was not statistically significant $(\mathrm{p}=0.094)$. LAL-A were negatively correlated with LDL-C, triglyceride and ALT (Figure 2).

Independent predictors of significantly reduced LAL activity in univariable predictive model included: chronic fatigue, hepatomegaly, splenomegaly, LDL-C, HDL-C, Triglyceride, AST and ALT levels. Our multivariable predictive model included: ALT, Triglyceride levels and hepatomegaly (Table 3 ).

The comparison of the group with significantly reduced LAL-A (Group 1) with the healthy control group in terms of oxidative stress and possible biomarker was presented in table 4.The median TBARS $14.38(5-37.5) \mathrm{mmol} / \mathrm{ml}$, Chitotriosidase 12.85 (2.59-500.67) $\mathrm{mmol} /$ $\mathrm{ml} / \mathrm{h}$, hs-CRP 3.33 (0.03-42.81) mg/L, Citokeratin (CK-18) 26.92 (2.58$52.8) \mathrm{ng} / \mathrm{ml}$ levels in Group 1 were higher compare to the controls $(\mathrm{p}$ $<0.005)$. MPO (1.12 (0.12-30.91)) $(\mathrm{U} / \mathrm{ml})$ levels were higher, too $(\mathrm{p}<$ 0.001) (table 4).

\section{Discussion}

The main outcome of our study was the fact that pediatric patients with liver dysfunction (persistent elevation in ALT and/or AST, hepatomegaly, hepatic steatosis) and/or dyslipidemia (high LDL-C ( $\geq$ $160 \mathrm{mg} / \mathrm{dl})$, low HDL-C $(\leq 35 \mathrm{mg} / \mathrm{dl}))$ may have a reduced LAL-A. The significantly reduced LAL-A was found in $14 \%$ of them. The other patients have a reduced, but sufficient enzyme levels. Nobody was enzyme deficient. It was reported that the enzyme activity between $0.15-0.40 \mathrm{nmol} / \mathrm{punch} / \mathrm{hour}$ could be related with LIPA gene heterozygous carriers [10]. But on the other hand, it was underlined 
Table 3. Univariable and multivariable predictive model for reduced LAL activity

\begin{tabular}{|l|c|c|c|c|c|c|}
\hline & \multicolumn{3}{|c|}{ Univariable predictive model } & \multicolumn{3}{c|}{$\begin{array}{c}\text { Multivariable } \\
\text { predictive model }\end{array}$} \\
\hline & OR & $95 \%$ CI & P & OR & $95 \%$ CI & P \\
\hline Chronic fatigue & 0.68 & $0.52-0.89$ & 0.006 & & & \\
\hline Hepatomegaly & 1.18 & $1.09-1.27$ & 0.000 & 1.28 & $1.10-1.48$ & 0.001 \\
\hline Splenomegaly & 0.32 & $0.16-0.65$ & 0.002 & & & \\
\hline $\begin{array}{l}\text { LDL-Cholesterol } \geq \\
160 \mathrm{mg} / \mathrm{dl}\end{array}$ & 0.238 & $0.031-1.802$ & 0.001 & & & \\
\hline $\begin{array}{l}\text { HDL- Cholesterol }< \\
35 \mathrm{mg} / \mathrm{dl}\end{array}$ & 0.163 & $0.056-0.474$ & 0.005 & & & \\
\hline $\begin{array}{l}\text { Trigliserid } \geq 150 \\
\mathrm{mg} / \mathrm{dl}\end{array}$ & 1.455 & $0.773-2.736$ & 0.000 & 2.28 & $1.73-2.68$ & 0.001 \\
\hline ALT $\geq 60 \mathrm{u} / 1$ & 1.819 & $0.964-3.434$ & 0.000 & 1.18 & $1.08-1.43$ & 0.001 \\
\hline AST $\geq 60 \mathrm{u} / 1$ & 0.947 & $0.486-1.847$ & 0.540 & & & \\
\hline
\end{tabular}

ALT: Alanine Aminotransferase; AST: Aspartate Aminotransferase; HDL: High-Density Lipoprotein Cholesterol; LDL: Low-Density Lipoprotein Cholesterol; OR: Odds Ratio

Table 4. Comparison of possible biomarkers measured in Group 1 and healthy control group

\begin{tabular}{|l|c|c|}
\hline & Control $(\mathbf{n}=\mathbf{4 0})$ & Grup1 $(\mathbf{L A L}<\mathbf{0 . 6})(\mathbf{n}=\mathbf{4 5})$ \\
\hline TBARS $(\mathrm{mmol} / \mathrm{ml}) *$ & $11.25(3.75-29.38)$ & $14.38(5-37.5)$ \\
\hline MPO $(\mathrm{U} / \mathrm{ml})^{* *}$ & $0.53(0.26-10.78)$ & $1.12(0.12-30.91)$ \\
\hline Chitotriosidase $(\mathrm{mmol} / \mathrm{ml} / \mathrm{h}) *$ & $12.85(2.59-50.67)$ & $14.57(3.73-77.7)$ \\
\hline hs-CRP $(\mathrm{mg} / \mathrm{L}) *$ & $2.56(0.13-13.09)$ & $3.33(0.03-42.81)$ \\
\hline Citokeratin $(\mathrm{CK}-18)(\mathrm{ng} / \mathrm{ml}) *$ & $21.04(2.2-34.93)$ & $26.92(2.58-52.8)$ \\
\hline
\end{tabular}

* Statistically significant difference between the two groups $(\mathrm{p}<0.05)$. ** Statistically significant difference between the two groups $(\mathrm{p}<0.001)$. TBARS: Thiobarbituric Acid Reactive Substances; MPO: Myeloperoxidase; hsCRP: High-Sensitivity C-Reactive Protein.

that it was not reliable approach to identify the carriers [11]. The fact that LAL activity was previously reported to be reduced in patients with severe liver disease, nonalcoholic fatty liver disease [12-17] brought us to idea to clarified the possible model of conditions related with significantly reduced LAL-A. Chronic fatigue, hepatomegaly, splenomegaly, elevated LDL-C, triglyceride, AST and ALT levels were determined as the most important clinical and laboratory factors associated with reduced LAL-A. Some of them were independently reported by different investigators [12-17]. For example, Shteyer et al. [12] reported no correlation between ALT and LAL, but Baratta et al. [15] found the negative one. On the other hand, our final multivariable predictive model included: only ALT, Triglyceride levels and hepatomegaly as factors which presence coexistence is predictable for significantly reduced LAL-A. Keep in mind that clinical course of CESD is widely variable this model will provide simple criteria for the first step of the screening.

The interesting and important finding of our study was the fact that triglyceride level demonstrated diagnostic predominance compare to the other lipid's components. The reason of these findings is probably hidden in the pathogenesis of the disease. Recent research demonstrated that the inability to hydrolyze triglycerides due to decreased LAL activity results in storage of triglycerides in liver lysosomes and increased triglyceride levels in blood. Then the decrease of intracellular free cholesterol leads to the 'up' regulation of HMGCoA reductase which can stimulate cholesterol synthesis; in addition, it also causes increases in VLDL cholesterol and LDL-C levels and this explains the dyslipidemia picture in LAL deficiency $[18,19]$.

High oxidative stress and macrophage activated parameters demonstrated in our study and reported previously in the literature [1] supported the hypothesis about increased oxidative status in patients with significantly reduced LAL-A. The differences between Group 1 and healthy controls were evaluated to test the hypothesis that lipid peroxidation might be increased in cases with significantly reduced LAL-A. The higher levels of TBARS, MPO, Chitotriosidase, hs-CRP and Citokeratin supported this hypothesis. Individually some of these biomarkers were reported by different researchers. Bernstein et al, stated that chitotriosidase can be used for the diagnosis and treatment followup in CESD, based on their review of 135 CESD clinical and laboratory findings [1]. It is well known that measurement of circulating CK-18 levels can be used as a noninvasive biomarker to determine the degree of steatohepatitis in non-alcoholic fatty liver disease. In the study of Gonzalez et al. [20] CK-18 levels were found to be increased in all liver diseases (fatty liver, alcoholic liver disease, chronic viral hepatitis, autoimmune hepatitis, cholestasis, transplantation, and hepatocellular carcinoma).

\section{Limitations}

The most important limitation of this study was the lack of genetic analysis of cases with significantly reduced LAL-A. Another milder limitation was small number of healthy control subjects.

Despite these limitations, to the best of our knowledge, there are no data in the literature evaluating possible predictive models for reduced LAL-A based on the data from broad spectrum and large pediatric population including dyslipidemic and hepatic features of CESD.

\section{Conclusion}

This study supports the concept that dyslipidemic pediatric patients and those with elevated transaminases have a reduced LAL-A. It provides a proof of concept about mean LAL-A (1.43 \pm 2.05 (0.03-16.8) $\mathrm{nmol} / \mathrm{ml} / \mathrm{h}$ ). In spite of the fact that no patients of LAL deficiency were identified, it supplies data about LAL significantly reduced LAL-A in that population (LAL activity $<0.6 \mathrm{nmol} / \mathrm{ml} / \mathrm{h}$ in $14 \%$ of the patients). On the other hand, the study clearly demonstrated that reduced LAL-A was correlated with biomarker like TBARS, MPO, chitotriosidase, hsCRP and CK-18. The main output of our study is creation of the multivariable predictive model for significantly reduced LAL-A which include: ALT, Triglyceride levels and hepatomegaly.

\section{Funding}

This study was funded by Ege University Scientific Research Project Coordination (2014TIP016)

\section{Ethical approval}

This study was approved by Ege University Medical Faculty Clinical Trials Ethical Committee (13-11/88)

\section{Acknowledgments}

The authors thank all the patients and their families for consenting to this study. The authors also wish to acknowledge Pelin Egrün for for the technical support.

\section{References}

1. Bernstein DL, Hulkova H, Bialer MG, Desnick RJ (2013) Cholesteryl ester storage disease: review of the findings in 135 reported patients with an underdiagnosed disease. J Hepatol 58: 1230-1243. [Crossref]

2. Stitziel NO, Fouchier SW, Sjouke B, Peloso GM, Moscoso AM, et al. (2013) Exome sequencing and directed clinical phenotyping diagnose cholesterol ester storage disease presenting as autosomal recessive hypercholesterolemia. Artericler Thromb Vasc Biol 33: 2909-2914. [Crossref]

3. Reiner Z, Guardamagna O, Nair D, Soran H, Hovingh K, et al. (2014) Lysosomal acid lipase deficiency an underreconized cause of dyslipidaemia and liver dysfunction. Atherosclerosis 235: 21-30. [Crossref] 
4. Porto AF (2014) Lysosomal acid lipase deficiency: diagnosis and treatment of Wolman and Cholesteryl Ester Storge Diseases. Pediatr Endocrinol Rev 12: S125-S132. [Crossref]

5. Muntoni S, Wiebusch H, Jansen-Rust M, Rust S, Schulte H, et al. (2013) Heterozygosity for lysosomal acidlipase E8 SJM mutation and serum lipid concentrations. Nutr Metab Cardiovasc Dis 23: 732-726. [Crossref]

6. Burton BK, Deegan PB, Enns GM, Guardamagna O, Horslen S, et al. (2015) Clinica features of lysosomal acid lipase deficiency - a longitudinal assessment of 48 children and adults. J Pediatr Gastroenterol Nutr 61: 619-625. [Crossref]

7. Baratta F, Pastori D, Ferro D, Carluccio G, Tozzi G, et al. (2019) Reduced lysosomal acid lipase activity: A new marker of liver disease severity across the clinical continuum of non-alcoholic fatty liver disease? World J Gastroenterol 25: 4172-4180. [Crossref]

8. Hamilton J, Jones I, Srivastava R, Galloway P (2012) A new method for the measurement of lysosomal acid lipase in dried blood spots using the inhibitör Lalistat 2. Clin Chim Acta 413: 1207-1210. [Crossref]

9. Cai CL, Zhou X, Zhao L, Yao XJ, Tu JC, et al. (2007) Optical detection of plasma chitotriosidase activity in healthy Chinese children using fluorescence spectrophotometry. Clin Chim Acta 379: 134-138.

10. Kuloğlu Z, Kansu A, Selbuz S, Kalaycı AG, Şahin G, et al. (2019) The frequency of lysosomal acid lipase deficiency in children with unexplained liver. $J$ Pediatr Gastroenterol Nutr 68: 371-376.

11. Lukacs Z, Barr M, Hamilton J (2017) Best practice in the measurement and interpretation of lysosomal acid lipase in dried blood spots using the inhibitor Lalistat 2. Clin Chim Acta 471: 201-205. [Crossref]

12. Shteyer E, Villenchik R, Mahamid M, Nator N, Safadi R (2016) Low serum lysosoma acid lipase activity correlates with advanced liver disease. Int J Mol Sci 17: 312. [Crossref]
13. Vespasiani-Gentilucci U, Gallo P, Piemonte F, Riva E, Porcari A, et al. (2016) Lysosomal acid lipase activity is reduced both in cryptogenic cirrhosis and in cirrhosis of known etiology. PLoS One 11: e0156113. [Crossref]

14. Vespasiani-Gentilucci U, D’Amico J, De Vincentis A, Tozzi G, Vorini F, et al. (2017) Platelet count may impact on lysosomal acid lipase activity determination in dried blood spot. Clin Biochem 50: 726-728. [Crossref]

15. Baratta F, Pastori D, Ferro D, Carluccio G, Tozzi G, et al. (2015) Reduced lysosoma acid lipase activity in adult patients with non-alcoholic fatty liver disease. EBioMedicine 25: $4172-4180$

16. Tovoli F, Napoli L, Negrini G, D'Addato S, Tozzi G, et al. (2017) A relative deficiency of lysosomal acid lypase activity characterizes non-alcoholic fatty liver disease. Int $J$ Mol Sci 18: 1134. [Crossref]

17. Selvakumar PK, Kabbany MN, Lopez R, Tozzi G, Alisi A, et al. (2016) Reduced lysosomal acid lipase activity - a potential role in the pathogenesis of non-alcoholic fatty liver disease in pediatric patients. Dig Liver Dis 48: 909-913. [Crossref]

18. Pisciotta L, Tozzi G, Travaglini L, Taurisano R, Lucchi T, et al. (2017) Molecular and clinical characterization of a series of patients with childhood-onset lysosomal acid lipase deficiency. Retrospective investigations, follow-up and detection of two novel LIPA pathogenic variants. Atherosclerosis 265: 124-132.

19. Guardamagna O, Abello F, Anfossi G, Pirro M (2011) Lipoprotein(a) and family history of cardiovascular disease in children with familial dyslipidemias. $J$ Pediatr 159: 314-319. [Crossref]

20. Gonzalez-Quintela A, Mallo N, Mella C, Campos J, Perez LF, et al. (2006) Serum levels of cytokeratin-18 (tissue polypeptide- spesific antigen) in liver diseases. Liver Int 6: 1217-1224. [Crossref]

Copyright: (2020 Özkaya B. This is an open-access article distributed under the terms of the Creative Commons Attribution License, which permits unrestricted use, distribution, and reproduction in any medium, provided the original author and source are credited. 